\title{
Evolution of Antimicrobial Resistance in Europe: A Factual Review
}

Marisa Eterna da Costa ${ }^{1}$ and Humberto S Machado ${ }^{1,2,3 *}$

${ }^{1}$ Serviço de Anestesiologia, Centro Hospitalar do Porto, Portugal

2 Instituto de Ciências Biomédicas Abel Salazar. Universidade do Porto, Portugal

${ }^{3}$ Centro de Investigação Clínica em Anestesiologia, Centro Hospitalar do Porto, Portugal

\section{Abstract}

Introduction and Objectives: The objective of this study was to conduct a review from the literature of the emergence of antimicrobial resistance, the spread of bacteria, their mutations, and policy strategies for the prevention and control of bacterial infections in Europe.

Materials and methods: A bibliographic survey was conducted for 2001 to 2016 on the Medline, Lilacs, Scielo, and Google Scholar databases; WHO reports-World Health Organization, ECDC - European Center for Disease Prevention and Control; SNS-National Health Service-Portuguese Republic and basic technical literature books. Searches were conducted in the Portuguese and English language.

Results: Resistance to antibiotics has been a worldwide public health problem. The European continent has suffered from the spread of multi-drug resistant bacteria. The literature indicates that antimicrobial resistance has increased significantly and that several factors are responsible for this increased resistance, such as the indiscriminate use of antibiotics in both animal food production and human health care, and that the agents of greatest epidemiological significance in Europe are methicillin-resistant Staphylococcus aureus (MRSA), vancomycinresistant Enterococcus (VRE), Enterobacteriaceae producing ESBLs, Acinetobacter spp and Pseudomonas spp.

Conclusion: Proper and rational use of antibiotics is of the utmost importance at present to avoid an epidemic of bacterial infections. Controlling the spread of resistant bacteria depends not only on correct therapeutic use, but also on basic measures of extreme importance.

Keywords: Antibiotics; Antibiotics-resistance; Conscious consumption; Prevention measures; Multi-Resistant bacteria; Bacterial infections; Public health

\section{Introduction and Objectives}

\section{The Story of Bacteria}

Bacteria are the oldest living beings in nature. Their basic structure is microscopic, single-cell, without nucleus, and they reproduce by binary division. They feed on almost all organic substances and, when sufficient nourishment is available, they multiply very quickly. In a period of 11 hours, one bacterium can produce 5 million other bacteria. Our bodies have 10 times more bacteria than human cells and they are responsible for many of the operations of our metabolism, such as digestion or the synthesis of vitamins. The microbiome in the human colon has more than 60,000 genes (twice as many as the human genome), in which only $1-5 \%$ of the DNA sequences are not bacterial [1].

Bacteria leave constituent traces of their ancestors, such as mitochondria, in the organelles of our cells that are responsible for the energy-producing processes of nearly all living beings. Nearly all of them are encased in a resistant external layer, with a cytoplasm membrane containing DNA, RNA, proteins and small molecules. Bacteria may be found alone or in colonies, and can live in the presence (aerobic) or absence (anaerobic) of oxygen. The Danish microbiologist, Hans Christian Gram, developed a quick method for classifying bacteria groupings based on their color after staining, with a Gram positive bacteria classification when the observed color was blue or purple and Gram negative when these properties where absent.

The objective of this study was to conduct a review from the literature of the emergence of antimicrobial resistance, the spread of bacteria, their mutations, and policy strategies for the prevention and control of bacterial infections in Europe.

\section{Materials and Methods}

A bibliographic survey was conducted for 2001 to 2016 on the Medline, Lilacs, Scielo, and Google Scholar databases; WHO reportsWorld Health Organization, ECDC-European Center for Disease Prevention and Control; SNS-National Health Service-Portuguese Republic and basic technical literature books. Searches were conducted in the Portuguese and English language.

\section{Results}

\section{Bacterial resistance}

Resistance may be considered an ecological phenomenon that occurs as a response by bacteria to the broad use of antibiotics and their presence in our environment. Bacteria multiply quickly, mutate, are promiscuous and can exchange genetic material between lines of the same species or different species. They are considered to be microorganisms that are highly capable of adapting to various factors, including exposure to powerful chemical agents [2].

This is the only living organism able to transfer genetic material between genes or between different species of bacteria [3].

*Corresponding author: Humberto S Machado, Serviço de Anestesiologia Centro Hospitalar do Porto, Instituto de Ciências Biomédicas Abel Salazar, Universidade do Porto, 4099-001 Porto, Portugal, Tel: +351-935848475; E-mail: hjs.machado@gmail.com

Received February 27, 2017; Accepted March 20, 2017; Published March 29 2017

Citation: da Costa ME, Machado HS (2017) Evolution of Antimicrobial Resistance in Europe: A Factual Review. J Allergy Ther 8: 250. doi:10.4172/2155-6121.1000250

Copyright: (C) 2017 da Costa ME, et al. This is an open-access article distributed under the terms of the Creative Commons Attribution License, which permits unrestricted use, distribution, and reproduction in any medium, provided the original author and source are credited. 


\section{Types of Resistance}

Bacteria have an extraordinary ability to adapt to their environment, including in the presence of antimicrobials.

Antimicrobial resistance (AMR) is the ability of a microorganism to resist the action of one or more antimicrobials.

AMR is a natural phenomenon caused by the mutation of bacteria. To acquire resistance, bacterium has to change its DNA, genetic material that occurs in two forms:

- The induction of mutation in the native DNA.

- The introduction of a foreign DNA, resistance genes that may be transferred between different genes or species of bacteria.

Bacteria use more than one strategy to avoid the action of antimicrobials [3].

\section{Intrinsic resistance}

This is insensitivity to an antimicrobial common to all of a single line (strain) of a given species. These are natural phenotypic characteristics of the microorganism. This phenotypic trace is vertically transmitted from one generation to the next without loss of the characteristics.

Phenotypic variations are fundamental to evolution and natural selection. The greatest determinants of intrinsic resistance are:

- The absence of the target in the bacteria where the antimicrobial acts.

- The antibiotic cannot penetrate the cell wall structure or cytoplasmic membrane.

This lineage multiplies in the concentrated presence of an antimicrobial, which is inhibitory for most of the category of the same species. Intrinsic resistance is hereditary, stable, irreversible and independent of the environment [3].

\section{Acquired resistance}

This occurs when resistance appears in bacterial species that was previously sensitive to a specific drug. This new property is the result of bacterial cell structural and/or a biochemical change caused by chromosomal and extra-chromosomal genetic alterations (plasmids), and is also a hereditary resistance that is stable, irreversible and independent of the environment [3].

Bacterial genomic change is divided into two categories:

Vertical transferal (Chromosomal): It refers to an informal and spontaneous mutation of the genetic material of the microorganism that makes it resistant to a given antibiotic.

Mutation is a random process that gives rise to new versions of genes, called "alleles".

Mutations are basic elements that allow the evolutionary process to take place. Mutation is a form of resistance common to many bacteria, viruses and funguses. For example: Staphylococcus aureus is resistant to rifampicin [3].

Horizontal transferal (extra-chromosomal): This is the most common means of acquiring resistance.

It occurs when a given microorganism receives genetic material from another resistant microorganism.
The bacteria that transmit the gene may be non-pathogenic but may develop and turn the resistance into a pathogen.

Horizontal resistance is facilitated by and dependent on movable genetic components: Plasmids, bacteriophages and transposons. This resistance may be transferred between numerous bacteria in several ways: Transformation, transduction, conjugation and transposition $[3,4]$.

Transformation: This is a process where there is lysis of a microorganism and release of its genetic material into the medium, and other bacteria can thus capture that DNA and incorporate it into its genome. That DNA may originate from chromosomes, plasmids or bacteriophages [3].

Transduction: This involves the accidental incorporation of chromosomal or plasmid bacterial DNA by a bacteriophage during its cell infection process. After cell lysis, this bacteriophage acts as a vector, and when it infects a new cell, it may insert the DNA containing the transferal gene and thus make it resistant. It occurs only between bacteria of the same species [3].

Conjugation: This is a process that requires physical contact between bacteria, thus transferring genetic material between them. The donor is called $\mathrm{F}+($ fertility+) and the recipient, F-. When it receives the genetic material in the form of plasmids, the recipient bacteria may become resistant. These plasmids transferred by conjugation may contain resistance genes for many antimicrobials and may select for multi-drug-resistant microorganisms [3].

Transportation: In transposition, short DNA segments known as "transposons" are found in the bacteria that may contain resistance genes for one or more antimicrobials. Transposons are not able to selfreplicate, so they "jump" within a cell. In uniting with the DNA for their replication, these jumping genes may incorporate a resistance gene into that DNA. Normal microbiota bacteria are the ones that carry the greatest amount of gene resistance [3].

Adaptive: This is an alteration in gene expression that suddenly arises due to environmental factors or in the presence of antimicrobials.

In contrast with intrinsic and acquired resistance, this resistance is not hereditary, is unstable, and reverts after the inductor stimulus is removed.

"Adaptive resistance is not considered relevant in the context of the worldwide increase in the resistance of pathogenic bacteria" [3].

Biofilms: A biofilm is a community of bacteria protected by a polymeric matrix produced by the bacteria themselves. This matrix makes it possible for the bacteria to adhere to a surface [4,5].

In the biofilm, the bacteria are more resistant to antimicrobial action due to:

- Reduced penetration of antibiotics;

- The presence of inactivating enzymes;

Limited growth, or growth under anaerobic conditions in the base of the biofilm.

- The presence of persister cells (a sub-population inside the biofilm that forms a single, highly-protected phenotypic state) [3].

Biofilm constitutes the most frequent cause of persistent infections and comprise more than $80 \%$ of bacterial infections 
in humans. Biofilm grows slowly, so the infections also manifest themselves slowly [4].

In humans, biofilm is present in our lungs (Pseudomonas aeruginosa, which causes the pneumonia associated with cystic fibrosis), vaginal infections, chronic wounds, chronic otitis, sinuses, adenoids, tonsils, the intestinal tract, the biliary pancreatic tract, and the mouth (dental plaque). These infections affect millions of people around the world and cause many deaths [5].

Biofilms spread through catheters, cardiac and vascular prostheses, sutures and IUDs [5].

\section{Mechanisms of Resistance}

\section{Reduction in antibacterial affinity for the recipient}

This is one of the most important clinically mechanisms of resistance. When chromosomal mutation causes a biochemical alteration of the target recipient of an antibiotic that impedes binding of the drug and its recipient in the bacteria [6].

- Mutation of the target.

The genes of the antimicrobials undergo a mutation that does not allow them to interact with the antibiotics, e.g.: DNA gyrase and topoisomerase, which is the target of quinolone [6].

\section{-Acquisition of a resistant form of the target.}

Staphylococci are resistant to methicillin due to their acquisition of a new PBP (enzymes involved in cell wall synthesis and targets for the action of beta-lactam antibiotics).

Their inhibition for these drugs causes weakness in the cell walls, which cannot withstand the osmotic difference, leading to bacterial cell lysis.

Streptococcus pneumonia acquire the PBP gene from the normal microbial population (oral Streptococcus), causing resistance to penicillin.

Methicillin-resistant S. pneumonia and S. aureus (MRSA), N. gonorrhea, and Haemophilus influenzae, are some of the microorganisms that become insensitive to the action of beta-lactam drugs through alterations in the PBP that reduce the drug's affinity for the enzymes [7].

\section{-Modification of the target.}

A recently acquired gene may modify a target, making it less vulnerable to a given antibiotic, e.g.: methylation of the ribosomal RNA that prevents the antibiotic from interacting with the ribosome. Macrolides and tetracycline [6].

\section{-Alternative routes (Metabolic Bypass)}

Sulphonamides act to inhibit the dihydropteroate synthetase involved in the synthesis of bacterial folic acid.

Some gram-negative bacilli synthesize an "altered" dihydropteroate via plasmids or transposons. In such cases, the bacteria have no affinity for sulpha drugs and become resistant to the drug, but maintain its biochemical action in the production of folates [8].

\section{Reduced entry}

- Decreased permeability of the External Membrane.

This membrane is responsible for giving a bacterial cell shape and rigidity, and serves as an osmotic barrier that enables the bacteria to retain nutrients, proteins and nucleic acids inside it and to keep certain substances on the outside.

The external membrane is typical and exclusive of gram-negative bacteria. The permeability of this membrane depends on the presence of special proteins, Porins, which create channels through which the substances can pass to the peri-plasmatic space and then to the cell's interior.

A change in the porins of the external cell membrane is responsible for the intrinsic resistance of gram-negative bacilli to penicillin, erythromycin, clindamycin, vancomycin, and for the resistance of Pseudomonas aeruginosa to trimethroprim [7].

\section{- Cytoplasmic Membrane}

This is located under the cell wall, is rich in phospholipids and is responsible for a cell's selective permeability, separating it from the exterior environment, as well as for exchanges with the exterior. It is also known as the phospholipid bilayer (a double sheet of phospholipid extract).

Antibiotics containing polymixins act only on the cytoplasmic membrane of gram-negative bacteria, destroying their osmotic properties and causing the departure of intra-cell compounds. They have a specific mechanism of action because they cause alteration of the cell structure instead of inhibiting the biosynthetic process, but are active in non-pathogenic bacteria and in eukaryotic cells. Since they are toxic, they are used only in topical treatments [9].

\section{Efflux pumps}

There are various mechanisms by which bacteria may resist the action of antibiotics.

When small molecules, or an antibiotic, are expelled from a bacteria cell, this is called efflux. This mechanism of resistance is not only selective for a class of antibiotics, but may also defend bacteria cells from various toxic compounds, including substances produced by the host, e.g. bile.

In the bacteria, the genes that encode the efflux pumps are located in the chromosomes or the plasmids.

Efflux pumps may be specific to one or more antibiotics. These pumps are associated with multi-drug resistance (MDR).

Efflux pumps are found in various antibiotics, such as: chloramphenicol, quinolones, tetracyclines and aminoglycosides.

Bacteria that express efflux pump MDR:

Gram-negative: Pseudomonas aeruginosa, Escherichia coli, Salmonella enteria, Neisseria gonorrhea.

Gram-positive: Staphylococcus aureus, Streptococcus pneumonia.

A mechanism that is common and predominant in various drug classes and divided into two classes: Beta-lactams and others [10].

\section{Enzymatic destruction}

This type of resistance means that enzymes degrade the antibiotic.

Bacteria may contain genes that encode the production of enzymes with the property of breaking or promoting structural changes in the drug, making it inactive against that microorganism.

It is a predominant and common mechanism in various drug classes: 
- Since the most common antibiotics are beta-lactams, the production of beta-lactamase by many pathogens as a resistance mechanism is one of the most common. This enzyme hydrolyses (destroys) the beta-lactam ring of the antibiotic, leaving the ring structure open so the drug is unable to bind to its receptor site, the PBPs, making it impossible to inhibit bacterial wall synthesis and totally cancelling its anti-bacterial activity. These PBPs are proteins located on the exterior side of the cytoplasmic membrane and the main targets of beta-lactam antibiotics (penicillins, cephalosporins, carbapenems and monobactams).

In gram-positives, the enzyme is released in the external environment, with the result that the drugs do not come into contact with the bacteria.

In gram-negatives, beta-lactamase production takes place at the level of the peri-plasmatic space (the space between the cell membrane and cell wall), where the antibiotic is neutralized.

There are currently more than one hundred known types of betalactamases. The bacteria with the highest production of beta-lactamase are enterobacter, pseudomonas, $H$. influenzae and S. aureus.

- Other enzymes that inactivate aminoglycosides are transferases.

Transferases introduce chemical groups at various points on the aminoglycosides, thus changing their activity, and provide resistance to chloraphenicol and macrolides.

- There are also bacterial enzymes, which, instead of breaking, change their shape, leading to the adenylation, acetylation and phosphorylation of aminoglycosides. Large numbers of these enzymes are found in pathogenic gram-negative bacteria [10].

\section{Percentage Level of Antibiotic Resistance In Europe}

The latest report from the European Antimicrobial Resistance Surveillance Network [11], shows that the increase in the level of antibiotic resistance in Europe varies greatly, depending on the type of bacteria, the antimicrobial resistance groups and the geographic region. In general, the lowest level of resistance is found in northern Europe and the highest level is in Southern and Eastern Europe.

These differences are mainly due to the improper use of antibiotics, infection treatment and hygiene practices [11].

This is cause for concern, due to gram-negative bacteria such as klebsiella pneumonia, Escherichia coli and Pseudomonas aeruginosa (with higher resistance than carbapenems) that have a level of resistance higher than 50\%, and acinetobacter.

The gram-positive bacteria are methicillin-resistant Staphylococcus aureus, which decreased from a level of $18 \%$ in 2011 to $17.4 \%$ in 2014 .

Streptococcus pneumonia was stable in the 2011-2014 period.

In 2014, Enterococcus fecalis resistance to vancomycin increased by more than 1/3 in European countries [11].

Antibiotic resistance has become a frightful public health problem in Europe and worldwide in terms of patients' health that is causing increased public health costs, treatment failures and deaths. For invasive bacterial infections, immediate treatment with an effective antibiotic is a key to reducing the risks of death.

The ECDC's analysis estimated that bacterial resistance was responsible for the death of 25,000 people per year in Europe, with a cost to government health services of 1.5 billion euros [6].
Cautious use of antibiotics, the prevention of infections, and strategic management in all medical sectors are required to prevent the promotion and transmission of bacterial resistance to antibiotics [11].

\section{Discussion}

Will be presented as figures the evidence of resistances that had the most significant increase.

\section{Gram negative bacteria}

Escherichia coli, Klebsiella pneumoniae, Pseudomonas aeruginosa and acinetobacter.

Escherichia coli (E.coli): Escherichia coli (E.coli) are the most common cause of blood infections, hospital-acquired urinary-tract infections, post-operative peritonitis, soft-tissue infections, and food poisoning. It may cause neonate meningitis.

Its resistance to amino-penicillin is widespread in Europe, at levels that varied in 2014 from 3.47\% in Finland to 73\% in Bulgaria. Increased in Bulgaria, Lithuania and Luxembourg.

In Italy, Spain and Portugal, resistance levels varied from 25 to $50 \%$.

In 2014, the general public in Europe had an average resistance level of $57.1 \%$ (Figure 1).

In 2014, Fluoroquinolones were estimated in 29 countries to vary from $7.8 \%$ in Island to $46.4 \%$ in Cyprus. Resistance levels are higher in southern and southeastern Europe. A significant increase was found in Belgium, Greece, Italy, Portugal and Sweden. In Portugal, the level is between 25 and $50 \%$.

In the general public in Europe, the average level increased 22.4\% in 2014 (Figure 2).

In 2014, resistance levels for 3rd-generation cephalosporin varied from $3.3 \%$ in Iceland to $40.4 \%$ in Bulgaria. Resistance levels increased greatly in Belgium, Bulgaria, the Czech Republic, France, Germany, Greece, Ireland, Norway, Portugal (from/by) $10 \%$ to $25 \%$, Slovenia and Sweden. The average for Europe increased from $9.6 \%$ in 2011 to $12.0 \%$ in 2014. Increased in Southern and Southeastern Europe (Figure 3).

For aminoglycosides: the level varied from $4.6 \%$ in Finland to 28.2\% in Bulgaria. Increased in Bulgaria, Croatia, Czech Republic, Ireland, Norway, Slovakia and Sweden. Portugal 10\% to $25 \%$.

In 2014, the average in Europe was 9.8\% (Figure 4).

For Carbapenem: resistance levels varied from $0 \%$ to $1.2 \%$ in Greece. Portugal <1\% [11].

Klebsiella pneumonia: Klebsiella pneumonia frequently colonizes the human gastrointestinal tract, but may also be found on the skin, in the ENT area and in the upper airways of hospital patients. They may spread rapidly between patients who are colonized but not infected, and from nurses' hands. The hands of healthcare professionals (promote) outbreaks and the spread of nosocomial infections: UTI, lower respiratory tract infections, and blood infections [11].

In Europe, the most common phenotypic resistance is the one common to [?] three groups of antibiotics: fluoroquinolones, 3rdgeneration cephalosporins and aminoglycosides. Between 2011 and 2014, this type of resistance increased significantly.

The highest level of resistance was found in southern Europe. It is $25 \%$ to $50 \%$ in Portugal and France, and more than $50 \%$ in Italy and Greece. 


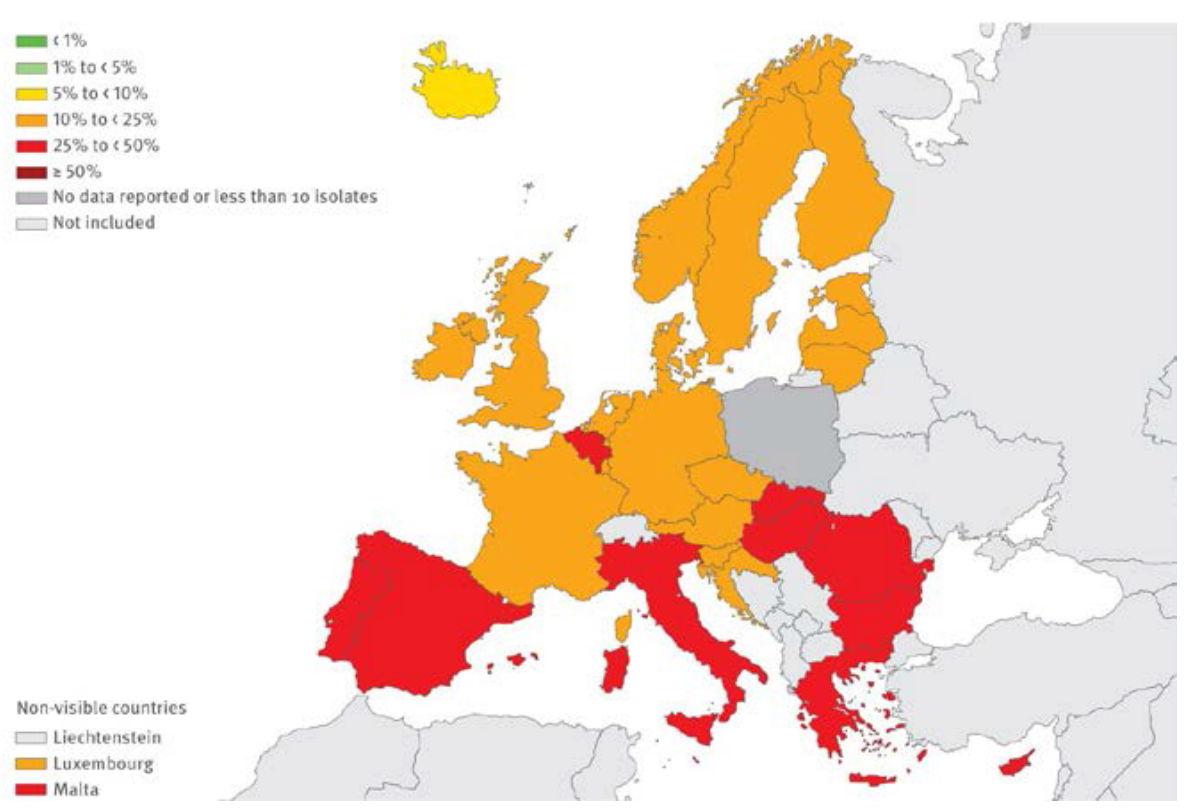

Figure 1: Escherichia coli. Percentage (\%) of invasive isolates with resistance to fluoroquinolones, by country, EU/EEA countries, 2014.

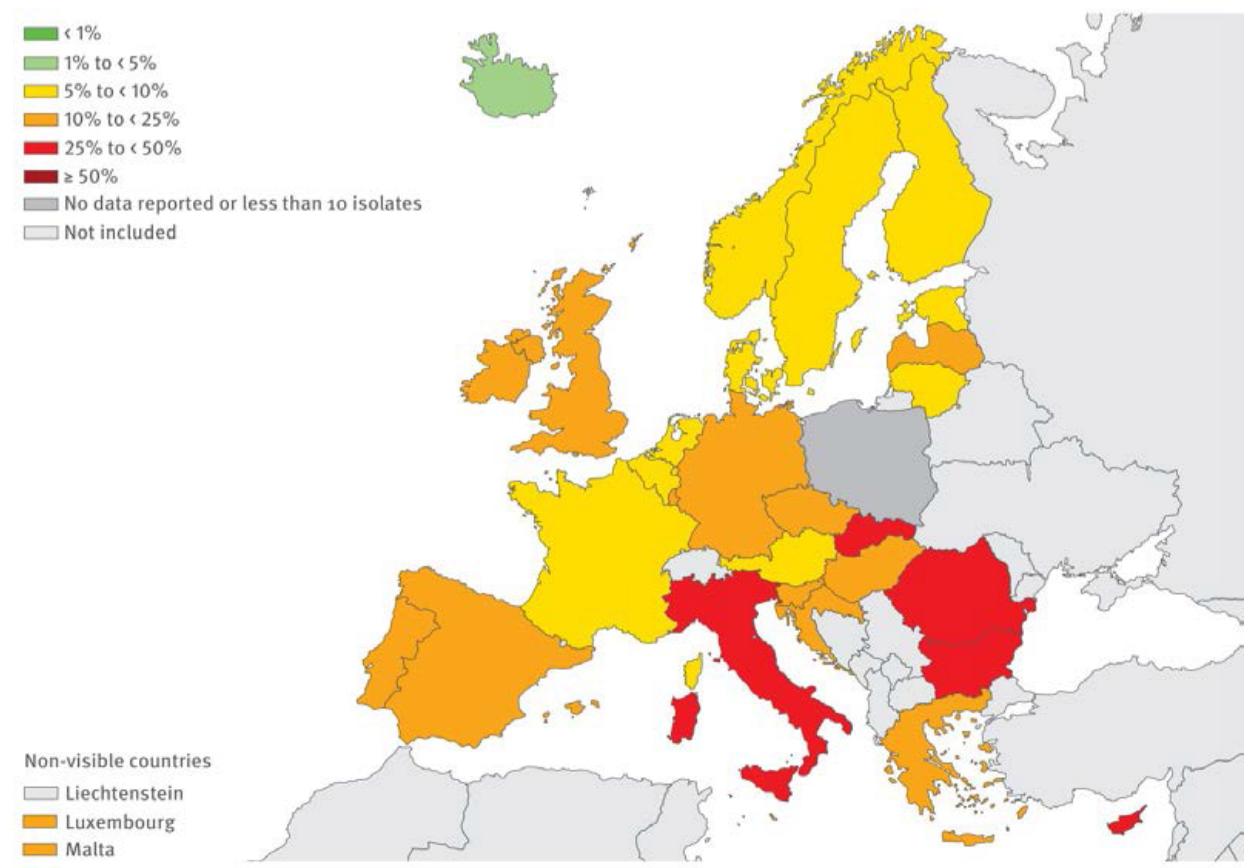

Figure 2: Escherichia Coli. Percentage (\%) of invasive isolates with resistance to third-generation cephalosporins, by country, EU/EEA countries, 2014.

Fluoroquinolone: Resistance in Europe varied from $3.6 \%$ in Iceland to $70.8 \%$ in Slovakia in 2014. Between 2011 and 2014, it showed a growth trend in 9 countries: Belgium, Finland, France, Ireland, Italy, Malta, Norway, Spain and the UK. Portugal $=36.5 \%$. The average increased significantly in the EU from $24.5 \%$ in 2011 to $27.4 \%$ in 2014 (Figure 5).

3rd-generation cephalosporin: has a level that varies in general in Europe in 2014 from 0\% in Iceland to 74.8\% in Bulgaria.

Significant increases were specifically found in France, Italy, Greece,
Norway, Portugal (40\%), Spain, the UK and Sweden.

In the general public in Europe, resistance to cephalosporin increased from $23.6 \%$ in 2011 to $28 \%$ in 2014.

$K$. pneumonia, in particular, is resistant to 3rd-generation cephalosporin and has a resistance level of $85 \%$ to $100 \%$ in 15 European countries.

The EU average increased from 23.6 in 2011 to $28.0 \%$ in 2014 (Figure 6). 


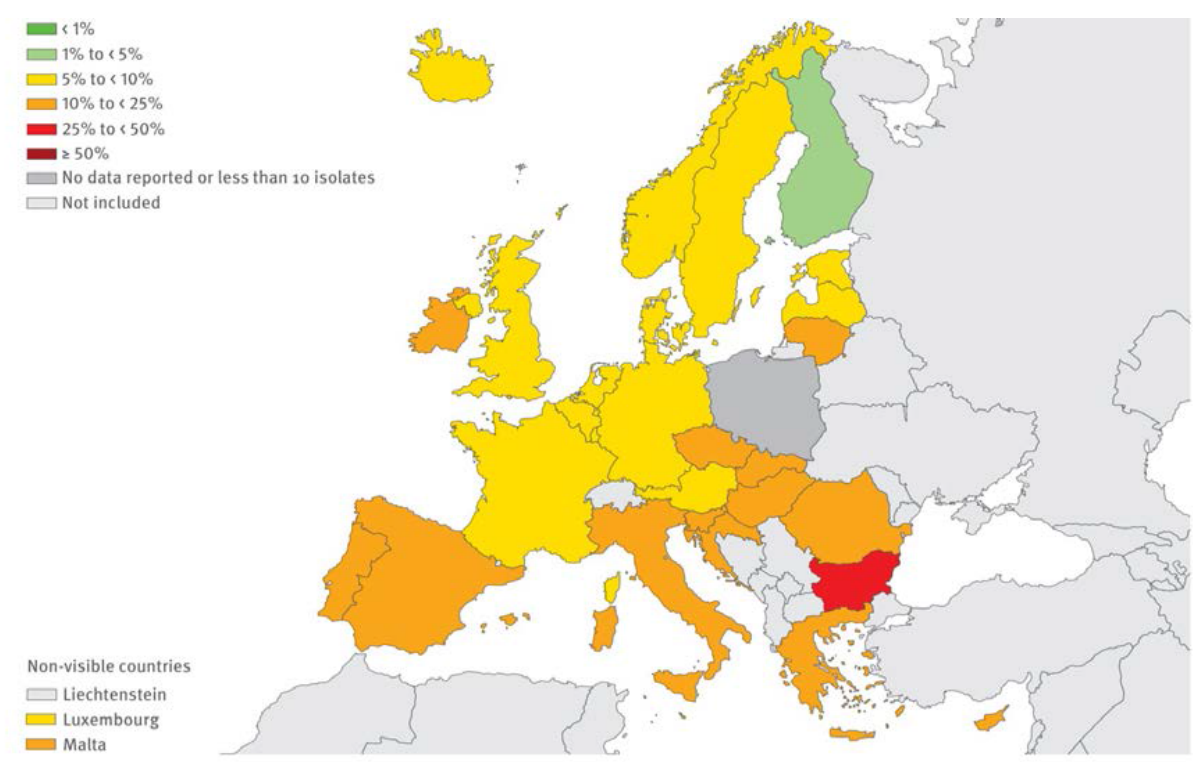

Figure 3: Escherichia Coli. Percentage (\%) of invasive isolates with resistance to aminoglycosides, by country, EU/EEA countries, 2014.

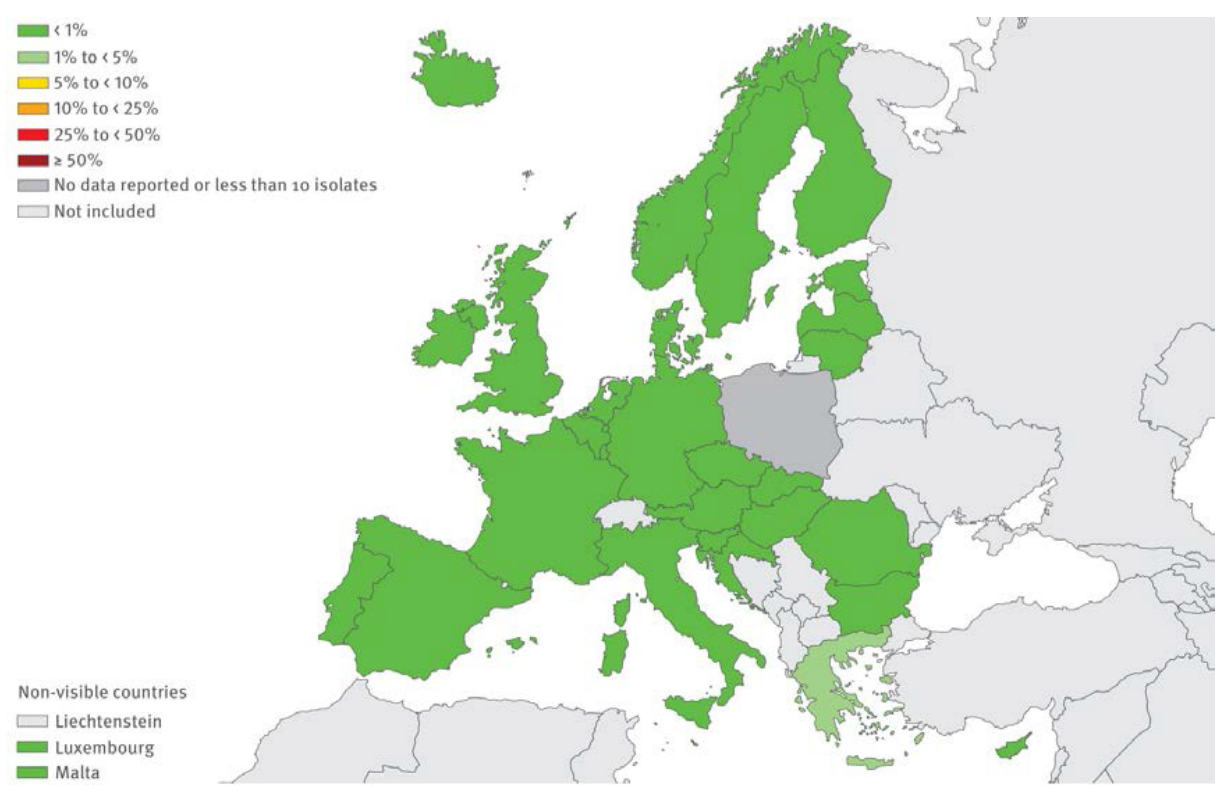

Figure 4: Escherichia Coli. Percentage (\%) of invasive isolates with resistance to carbapenems, by country, EU/EEA countries, 2014

Aminoglycosides: had a resistance level of $2.3 \%$ in Finland and 68.2\% in the Czech Republic in 2014. Increased in Finland, Czech Republic, France, Ireland, Italy, Malta, Norway and Spain.

The average resistance to aminoglycosides in Europe from $20.1 \%$ in 2011 to $23.1 \%$ in 2014 (Figure 7).

Carbapenem: Resistance to this group of antibiotics ranged from $62.3 \%$ in Greece in 2011 to $7.3 \%$ in 2014. Increased in Bulgaria, Coroatia, France, Germany, Italy, Portugal, and Spain. UE Increased from $6.0 \%$ in 2011 to 7.3 in 2014 (Figure 8).

K. pneumonia had a combined resistance to: 3rd-generation cephalosporin, fluoroquinolone and aminoglycosides. The average resistance in Europe increased from 16.7\% in 2011 to $19.6 \%$ in 2014. Portugal $=23.0 \%$.

K. pneumonia antibiotic resistance is considered a grave public health threat (Figure 9).

Pseudomonas Aeruginosa: Is found in aquatic environments and in nature. It is an opportunistic pathogen for plants and humans and is the most common cause of infection in hospitalized patients. It causes pneumonia, blood infections and UTI.

Due to its universal presence and versatility, it is very hard to control in hospital environments. It also causes skin infections and earaches, and may colonize patients with cystic fibrosis. It is 


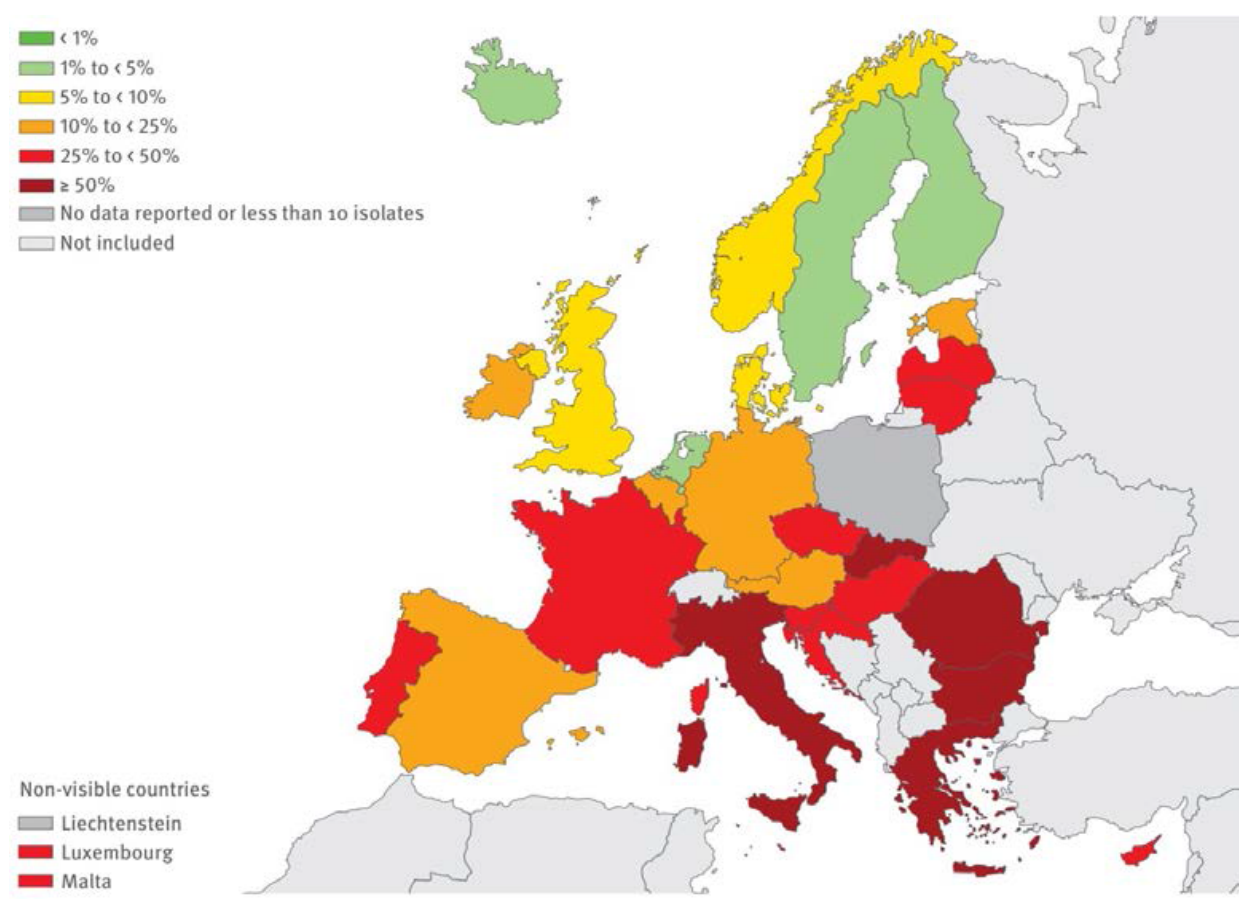

Figure 5: Klebisiella pneumoniae. Percentage (\%) of invasive isolates with resistance to fluoroquinolones, by country, UE/EEA countries, 2014.

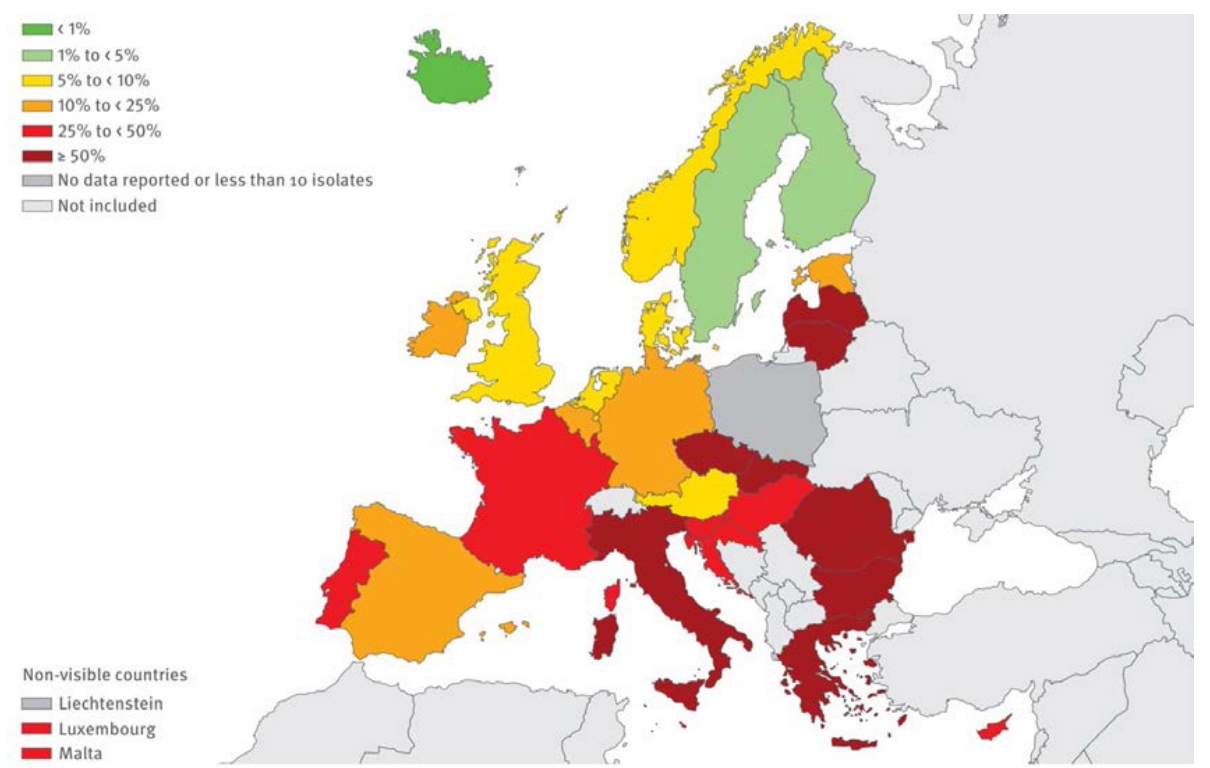

Figure 6: Klebisiella pneumonia. Percentage (\%) of invasive isolates with resistance to Third- generation cephalosporins, by country, UE/EEA countries, 2014.

highly present in major burn units, where it is almost impossible to eradicate [12].

Piperacillin+Tazobactam: Ranged from $4.4 \%$ in Denmark to $62.2 \%$ in Romania.

Increased in Hungary, Italy, Portugal and Slovenia. In Europe the level of resistance increased from 16\% in 2011 to $16.9 \%$ in 2014 (Figure 10).

Ceftazidime: Increases in resistance were found to range from $2.4 \%$ in Luxembourg to $59.1 \%$ in Romania.
The EU average rose from $12.8 \%$ in 2011 to $13.1 \%$ in 2014 (Figure 11).

Fluoroquinolone: Resistance in EU populations showed a significant decrease of $22.1 \%$ to $19.4 \%$ in 2014 .

Aminoglycosides: The level in Sweden changed by $0.6 \%$ and in Romania by $63.4 \%$.

Average resistance in the EU decreased significantly from $16.7 \%$ in 2011 to $14.8 \%$ in 2014 . 


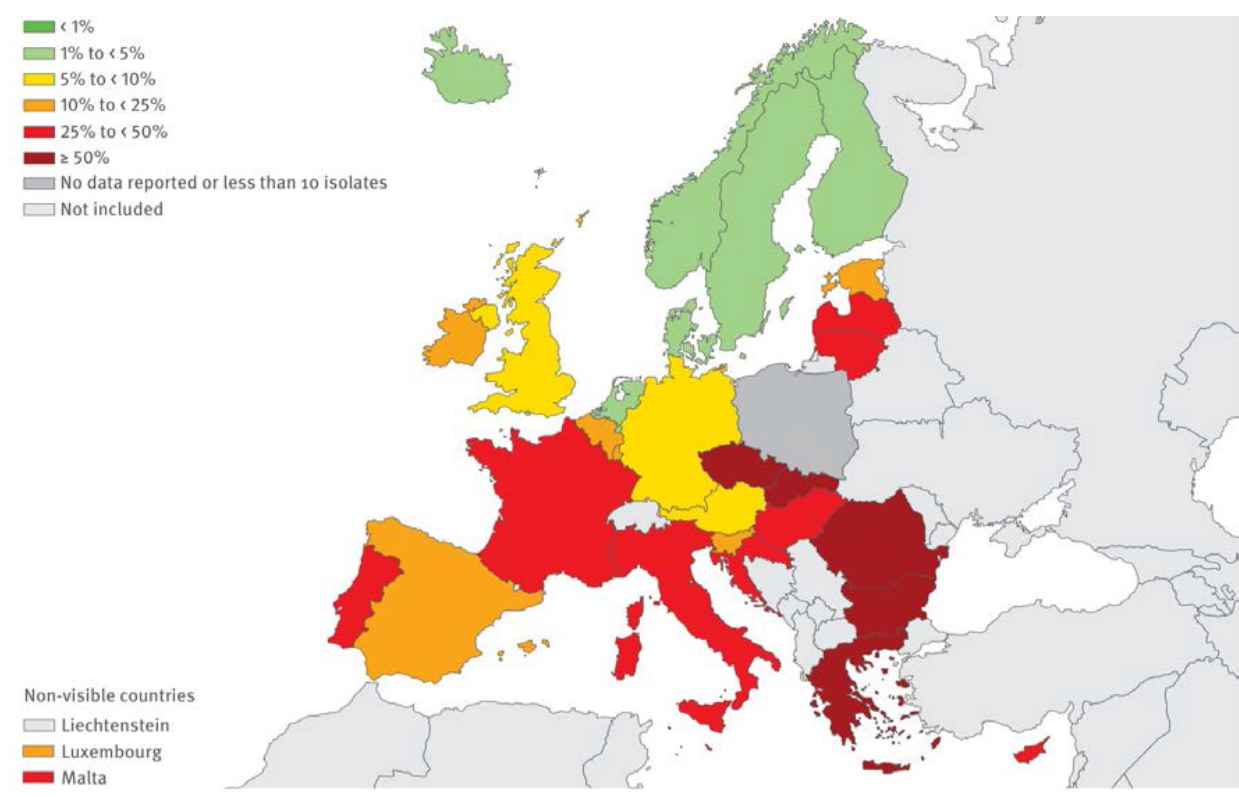

Figure 7: Klebisiella pneumonia. Percentage (\%) of invasive isolates with resistance to aminoglycosides, by country, UE/EEA countries, 2014.

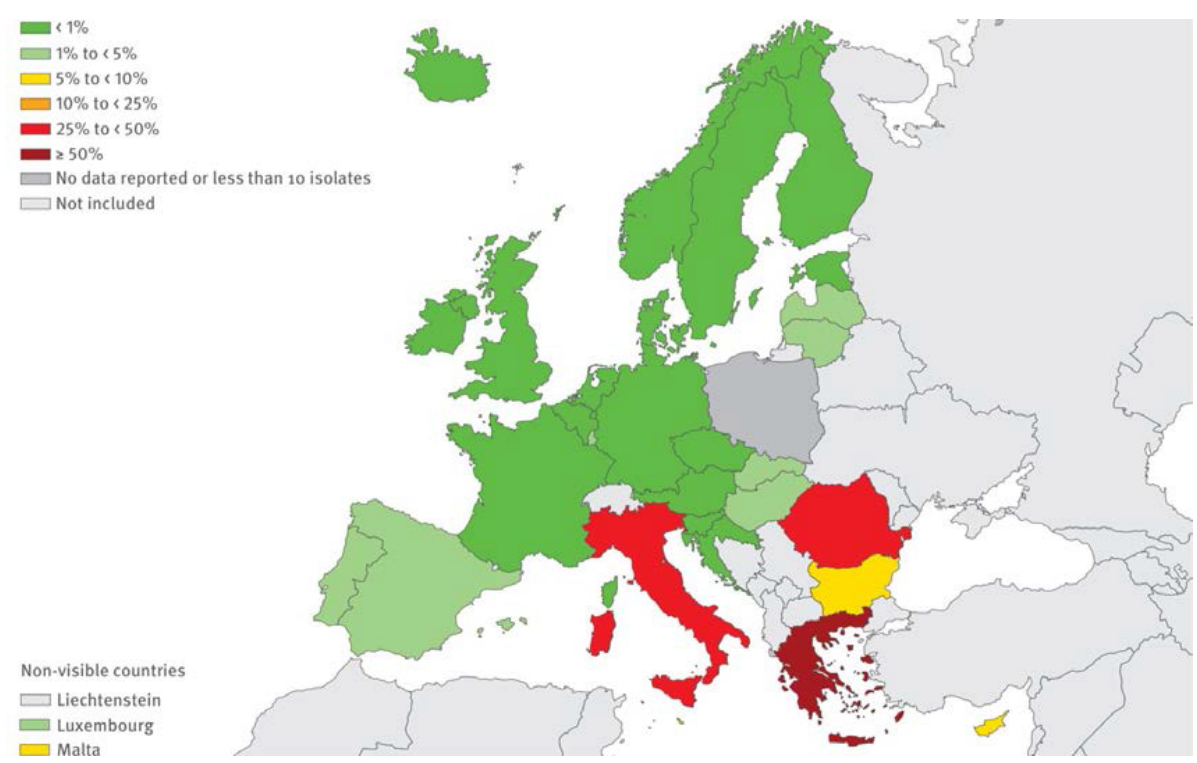

Figure 8: Klebsiella pneumonia. Percentage (\%) of invasive isolates with resistance to carbapenems, by country, UE/EEA countries, 2014.

Carbapenem: Showed a level of $4.4 \%$ in the Netherlands and $58.5 \%$ in Romania. Increased in Germany, Hungary and Slovakia.

The EU average showed an increase from $16.8 \%$ in 2011 to $18.3 \%$ in 2014 (Figure 12).

In 2014 , combined resistance to all of the above-mentioned antibiotics was stable at $13.3 \%$ [11].

Acinetobacter: These bacteria have low pathogenicity and most are environmental species. They belong to the A. Baumannii group (comprising the A. Baumannii, A. Pitti and A. nasocomialis species).
It is resistant to most antibiotics.

In 2014, fluoroquinolones showed a resistance level of $2.9 \%$ in Denmark and 95.3\% in Greece.

Aminoglycosides: Aminoglycosides had a resistance level in 2014 of $1.7 \%$ in Denmark and $89.1 \%$ in Italy.

Carbapenems: Carbapenems showed $0 \%$ resistance in the Netherlands and $93.2 \%$ in Greece.

Combined resistance to all of the above-mentioned antibiotics ranged from $0 \%$ in Finland, Denmark and the Netherlands to $86.9 \%$ in Greece, in 2014. 


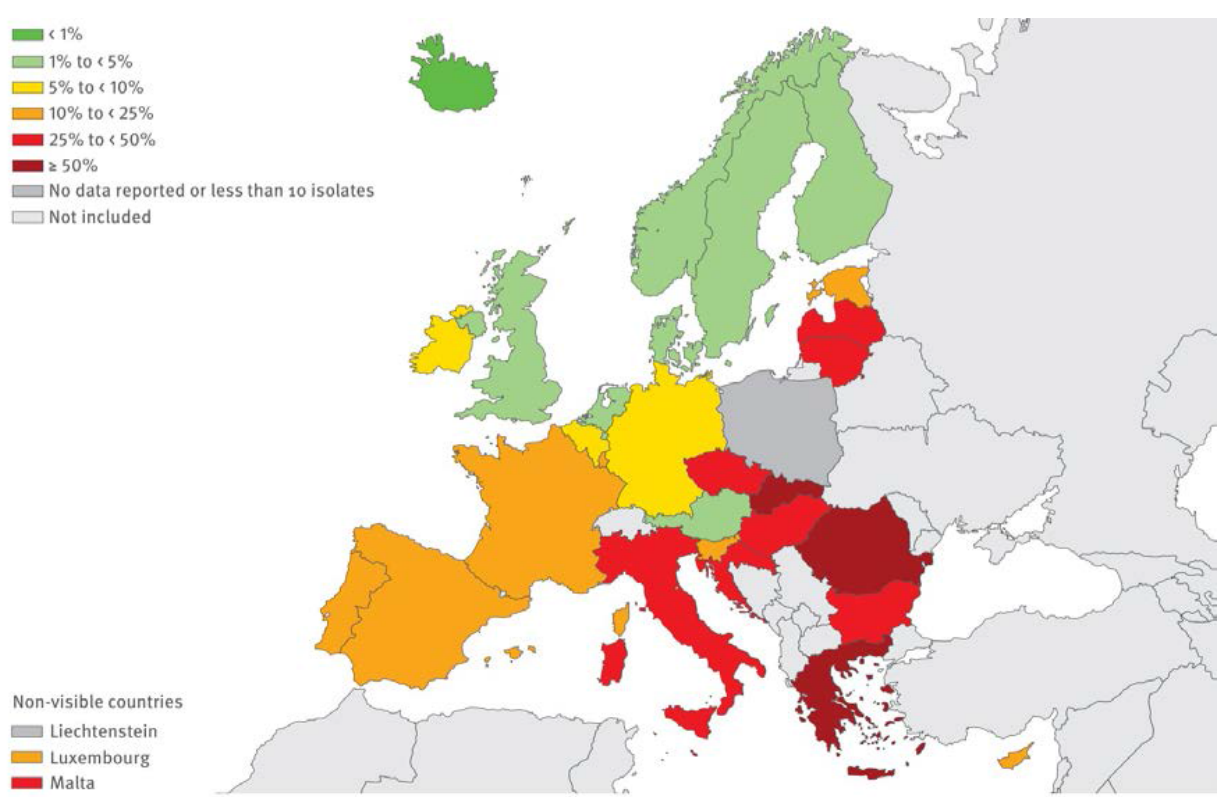

Figure 9: Klebsiella pneumonia. Percentage (\%) of invasive isolates with resistance to fluoroquinolones, third-generation cephalosporins and aminoglycosides, by country, UE/EEA countries, 2014

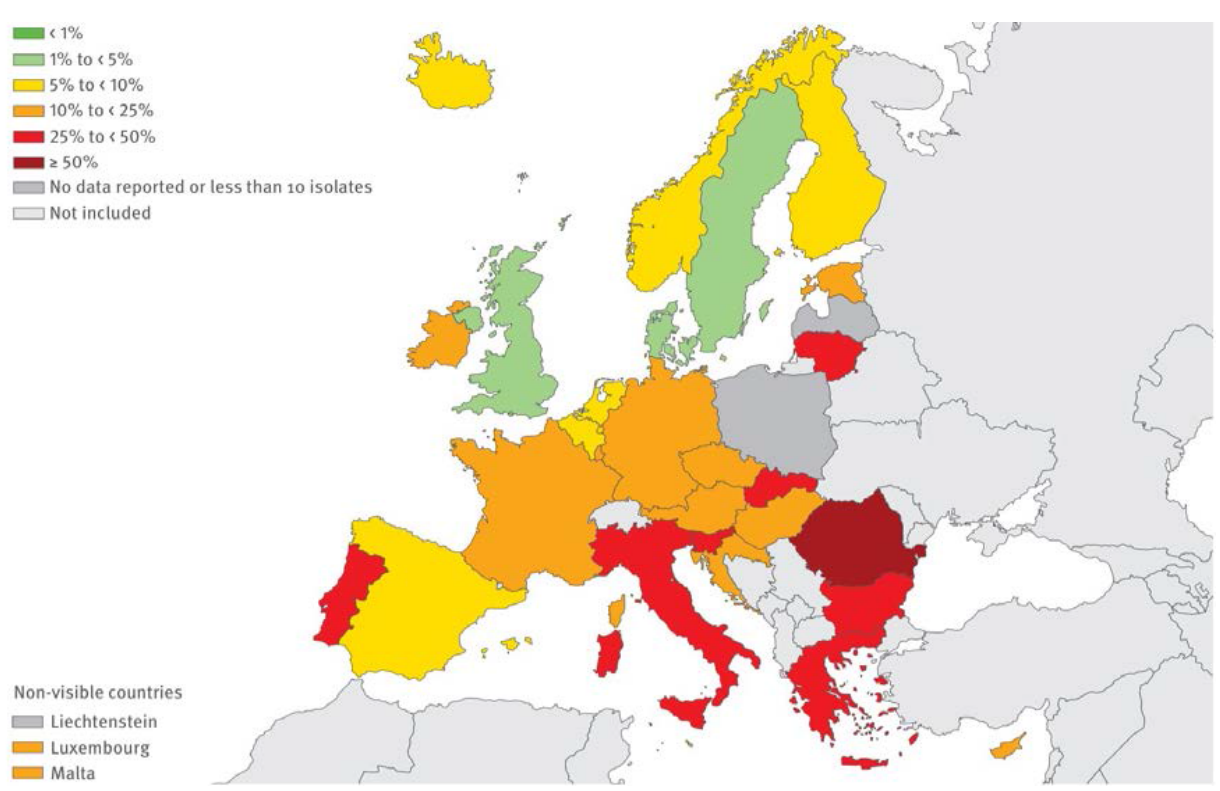

Figure 10: Pseudomonas Aeruginosa. Percentage (\%) of invasive isolates with resistance to piperacillin+tazobactam, by country, UE/EEA countries, 2014

The presence of Acinetobacter spp. in hospitals is of great concern because the bacteria can persist in the environment for long periods of time and is very hard to eradicate.

Polymixins: More than $4.0 \%$ are resistant to polymixins, and most were found in (8.0\%) Greece and Italy.

Acinobacter Spp. Showed High resistence in the Baltic countries, southern and South-eastern Europe [11].

\section{Gram Positive Bacteria}

Streptococcus Pneumoniae, Staphylococcus Aureus and Enterococcus.
Streptococcus pneumonia: Streptococcus pneumonia is the main causative agent of community-acquired respiratory infections (ear aches, sinusitis and pneumonia, meningitis, endocarditis, peritonitis, osteomyelitis and septic arthritis). High mortality.

The S. pneumonia wall is encased with a viscous polysaccharide that protects the bacteria from antibody adhesion and from destruction by leukocytes.

Penicillin resistance was stable. The resistance levels found in 2014 were $0 \%$ in Cyprus and $46.7 \%$ in Romania. Levels increased in Italy and Sweden. 


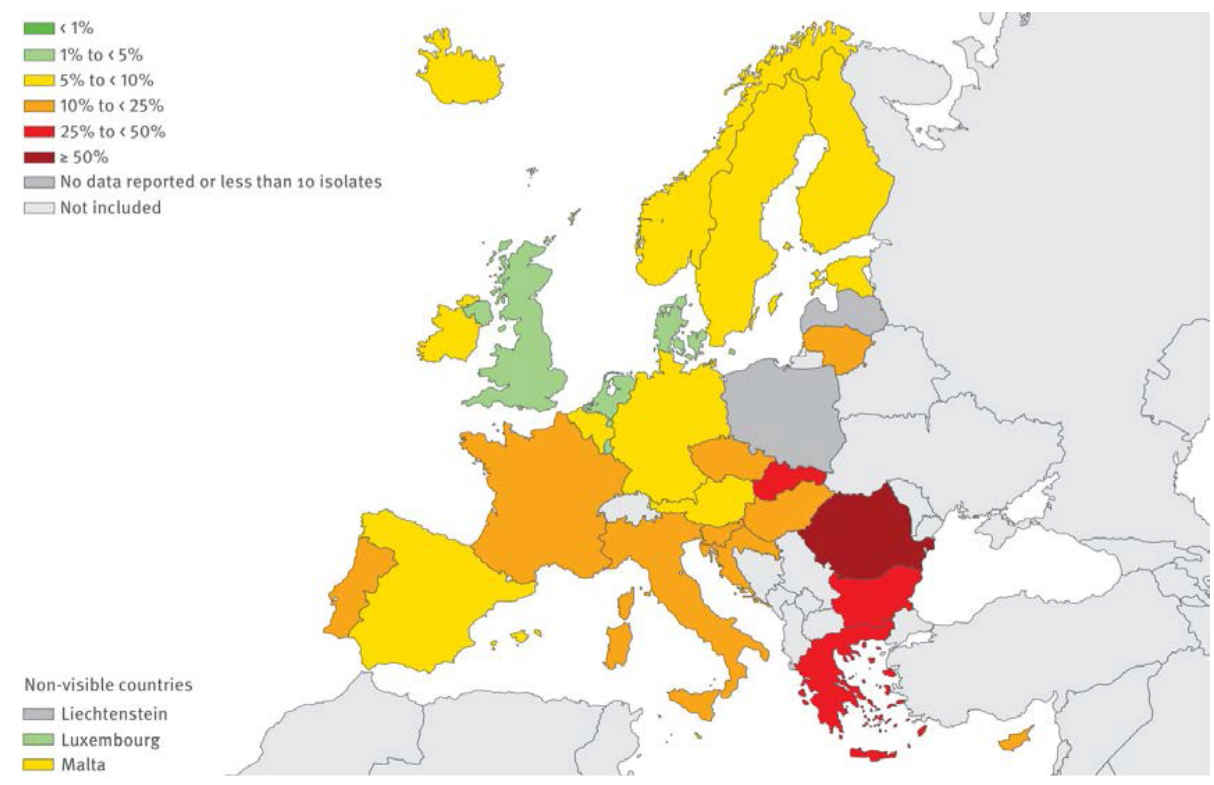

Figure 11: Pseudomonas Aeruginosa. Percentage (\%) of invasive isolates with resistance to ceftazidime, by country, UE/EEA countries, 2014.

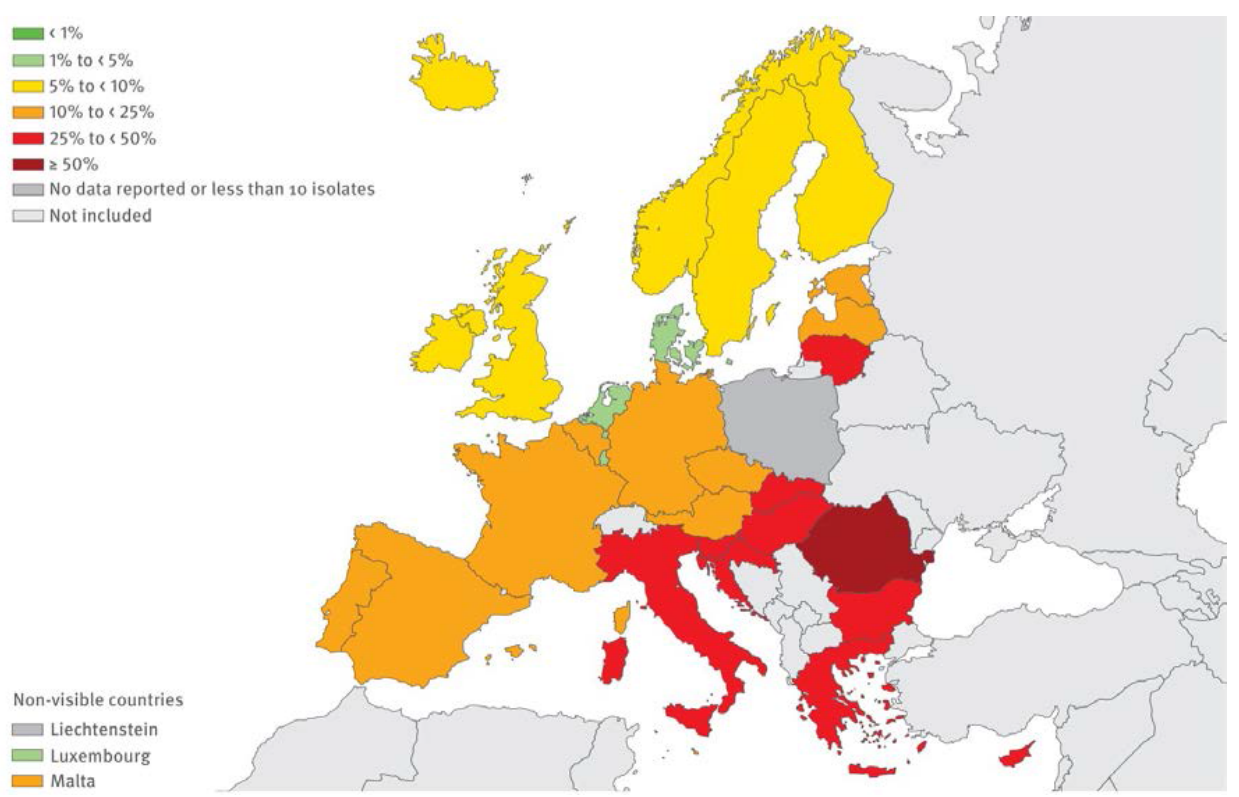

Figure 12: Pseudomonas Aeruginosa. Percentage (\%) of invasive isolates with resistance to carbapenem, by country, UE/EEA countries, 2014.

Macrolides: Macrolides showed a significant reduction in resistance in Slovenia, Finland and Belgium. In 2014, resistance levels ranged from $0 \%$ in Cyprus to $48.0 \%$ in Romania.

Portugal from $10 \%$ to $25 \%$ resistance rate.

For Penicillin and Macrolides combined the resistance ranged from 0\% in Cyprus to $37.8 \%$ in Romania.

In Europe, vaccinations increased for children - using the pneumococcus conjugated vaccine (PCV), and for the elderly, children under 1 year of age and immune-depressed persons - using the polysaccharide vaccine [11].
Staphylococcus Aureus: This is associated with community-based infections and nosocomial infections such as: skin infections (cellulitis, impetigo) and wounds in various places, bacteremia, pneumonia, osteomyelitis, endocarditis, myocarditis, pericarditis and meningitis [12].

Its methicillin-resistant staphylococcus aureus (MRSA) form was the most common cause of antibiotic resistance in healthcare the world over.

This high MRSA rate causes increase time in hospital and high mortality, consequently resulting in increased costs.

Beta-Lactams: In Europe, the resistance level varied from $0.9 \%$ to 
$56 \%$, and was higher in the south and south-west but lower in the north of Europe. Portugal has 25\% to 50\%.

Conclusion: The European average for MRSA decreased from $18.6 \%$ in 2011 to $17.4 \%$ in 2014 .

Despite efforts directed at all healthcare sectors to reduce MRSA, community-based infections caused by MRSA increased in Europe, which is evidence of the transfer of MRSA clones from hospital environments to the community [11].

Enterococcus: This is an organism that usually colonizes the intestine and female genital tract. It may, however, cause a variety of infections such as endocarditis, blood infections, UTI and peritonitis. This happens when the guest/host relationship is interrupted. Most infections in humans are caused by E. faecalis (80-90\%) and E. faecium (10\%) [12].

Aminoglycosides: High-Level of resistance, ranged from 8.3\% in Iceland to $76.5 \%$ in Romania. Portugal 32.6\% in 2014.

The average in the EU decreased from $33.9 \%$ in 2011 to $28.8 \%$ in 2014.

\section{Enterococcus faecium}

\section{Vancomycin}

Resistance was found in France for the first time and showed a great increase in recent years in the U.E., from $6.2 \%$ in 2011 to $7.9 \%$ in 2014.

Level ranges from 0\% in Estonia, Finland, Iceland and Malta to 45.1\% in Ireland in 2014. Increased in Bulgaria, Croatia, Denmark, Hungary, Ireland, Italy, Slovakia and UK.

Level of resistance to aminoglycosides in Portugal of $25 \%$ to $50 \%$ and to vancomycin $10 \%$ to $25 \%$. (Figure 13) [11].

\section{Antibiotic Use in Animals}

According to the WHO report, the use of antibiotics in healthy animals, and in food production, has increased significantly, since their use is designed to protect and fatten the animals (raising farm animals, fowl and fish) but there are no scientific/research records that show the need for or benefits from the use of antibiotics on a large scale in animal production [13].

In Belgium, the prevalence of, and susceptibility to methicillinresistant Staphylococcus aureus (MRSA) was recorded in a random study done in 50 farms (breeding and fattening), and nasal samples were taken from 1,500 pigs, in which the strains of MRSA showed resistance to tetracycline and additional resistance to trimethoprim, lincosamides, macrolides, aminoglycosides and fluoroquinolones [14]. MRSA was found in reindeer killed in Finland and Norway.

\section{Resistance to Antibiotics}

During the last decade, an increase has been found in the antibiotic resistance levels of the principal pathogenic agents, mostly in Gramnegative bacteria (K. pneumoniae, E. coli and P. aeruginosa). Infections complicated by multi-drug resistant (MDR), extremely drug-resistant (XDR) and completely resistant (PDR - Pandrug-resistant) isolates are increasingly common and thus hard to treat. The excessive and inappropriate use of antibiotics, in both human and animal medicine, has been acknowledged as one of the causes of the problem, and constitutes a major factor in selective pressure leading to the emergence and spread of resistant bacteria and/or genes resistant to antibiotics. The clinical effect of antibiotic resistance demands study of the mechanisms involved in order to contribute to rapid and oriented adaptation of treatments, as well as to epidemiological monitoring and control [15].

Resistance to antibiotics has serious clinical and economic consequences related to the increase in morbidity and mortality, due to delays in administering effective treatment for the infections caused by resistant bacteria. Prolonged hospital stays and the use of antibiotics other than those for first-line use have significantly increased healthcare costs [16].

Bacterial resistance has grown sharply and the Gram-positive bacteria most resistant to antibiotics are of the Staphylococcus aureus

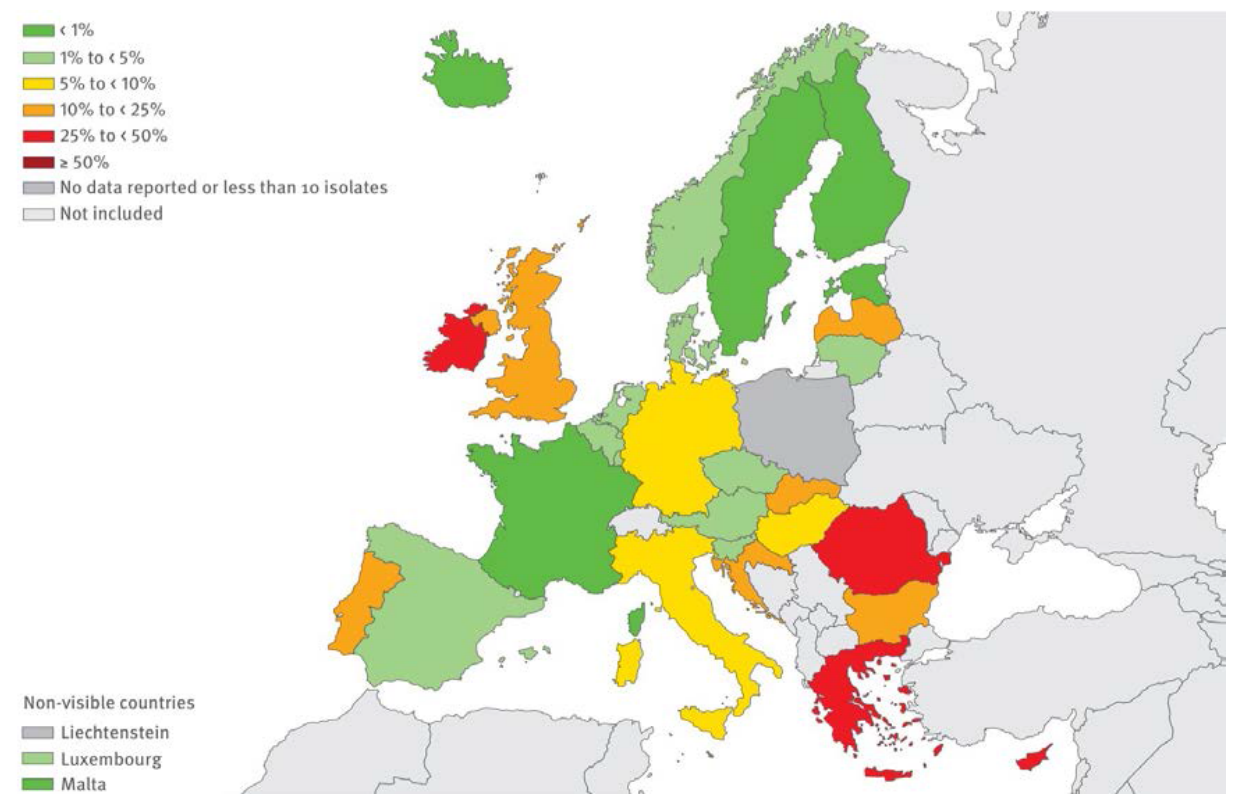

Figure 13: Enterococcus Faecium. Percentage (\%) of invasive isolates with resistance to vancomycin, by country, UE/EEA countries, 2014 . 
species and the Enterococcus genus, whereas the Gram-negative bacteria most resistant to antibiotics are of the Acinetobacter Baumannii and Pseudomonas aeruginosa species and from the Enterobacteriaceae family [17].

On 30 August 3016, new therapy guidelines for the treatment of three sexually transmitted infections (STIs) were issued by the WHO due to the increasing threat from resistance to antibiotics. It is estimated that, every year, 131 million people are infected with chlamydia, 78 million with gonorrhea, and 5.6 million with syphilis [13].

Antibiotics were the most effective drugs of all medications. Their success is reflected in their continuing use and the reduction in morbidity and mortality due to bacterial infections over the last 50 years $[18,19]$.

The WHO's global plan to contain antibiotic resistance, published in 2001, established a set of broad recommendations to control drugresistance. The bacteria that cause common infections have developed a resistance to every new antibiotic invented, and drug-resistance has grown, becoming a worldwide threat to public health. With a scarcity of new drugs on the market, the need for measures to prevent a global crisis in healthcare is ever more urgent. In addition to constituting a huge financial burden that the budgets of national health departments can ill afford, drug resistance has economic consequences well beyond the healthcare sector, with nefarious effects on international travel and trade, as a reflection of the cross-border spread of resistant infections. We know how and why drug-resistance develops, which factors promote its occurrence and spread, and what measures need to be taken to control it [19]. Drug resistance to antibiotics increases the duration of diseases and the risk of death. Healthcare costs also increase with ever-longer hospital stays and the need for intensive care measures [11].

\section{Antibiotic Resistance in Portugal}

In the European context, Portugal is still a country with elevated use of antibiotics, even though the use of these drugs has decreased in recent years. (According to the ECDC, Portugal is the country with the highest rate of hospital infections and the highest rates of resistance recorded in Europe (Table 1) [20].

\section{Means of Action}

\section{Surveillance}

Antibiotic resistance is a worldwide, public policy problem. The

\begin{tabular}{|l|c|}
\hline \multicolumn{2}{|c|}{ Distribution by type of hospital infection (HI) } \\
\hline Pneumonias & $23.20 \%$ \\
\hline Other lower respiratory tract infections & $5.60 \%$ \\
\hline Surgical site infections & $15.70 \%$ \\
\hline UTI & $23.20 \%$ \\
\hline Bacteremias & $7.60 \%$ \\
\hline Catheter-related infections (without bacteremia) & $1.50 \%$ \\
\hline Gastrointestinal infections & $6.10 \%$ \\
\hline Skin and soft-tissue infections & $5.00 \%$ \\
\hline Bone and cartilage infections & $2.40 \%$ \\
\hline Nervous system infections & $0.90 \%$ \\
\hline Eye, ear and mouth infections & $2.10 \%$ \\
\hline Reproductive tract infections & $0.40 \%$ \\
\hline Systemic infections & $4.70 \%$ \\
\hline
\end{tabular}

Table 1: Prevalence of $\mathrm{HI}$ by type of infection in Portugal (adapted from the ECDC - Point prevalence survey of healthcare - Associated Infections and Antimicrobial Use in European Acute Care Hospitals, Stockholm 2013).
$\mathrm{EU}$ is investing in awareness campaigns for the general public and the medical community on the importance of proper prescription and use of antibiotics. World Awareness Week on the use of antibiotics is a WHO project that started in November 2015 in the interest of promoting awareness of worldwide resistance to antibiotics and to promote best practices among the general public, healthcare professionals, and competent decision-making bodies [13].

On 27 February 2017, WHO published its first list of antibioticresistant "priority pathogens."

This list is intended to stimulate the government to create new policies by encouraging public and private agencies to invest in the research of new antibiotics.

The WHO list comprises three categories divided second the urgency of the need for new antibacterials.

1. Criticism: Acinobacter Baumanni; Pseudomonas aeroginosa; Enterobacteriaceae.

2. High: Enterococcus Faecium; Staphylococcus Aureus, Helicobacter Pylori; Campylobacter Spp.; Salmonellae; Neisseria Gonorrhoeae.

\section{Average}

Streptococcus Pneumonia; Haemophilus Influenzae; Shigella Spp.

In Europe, the ECDC (European Centre for Disease Prevention and Control) is a surveillance and information system connected to all European countries that analyses the data for 52 transmissible diseases, drawn from all the countries in Europe using the TESSY European surveillance system [11].

The "Burden of Resistance and Disease in European Nations (Carga) analyses data on the costs of diseases and of antibiotics resistance in Europe in order to promote awareness of this problem among politicians and the general public [20].

\section{Prevention of Infections}

Increased efforts are needed to reduce the spread of resistant pathogens in the community and in hospitals by:

\section{- Improving hygiene}

- Preventing improper use of antibiotics.

The excessive use of antibiotics as a prophylactic for travellers, improper antibiotic prescription, non-compliance with antibiotic usage periods, and inappropriate antibiotic selection. One example of this is the prescription of antibiotics to treat viral infections such as colds, where the use of antibiotics produces no effect.

Reduce the use of antibiotics and maintain a grace period of 48 hours before prescribing them in the hope that the condition will spontaneously disappear.

Agricultural sector Non-therapeutic use of antibiotics to promote growth is currently prohibited in Europe.

More than $70 \%$ of the antibiotics used in the U.S. go to feed animals (fowl, pigs and cattle), even when they are disease-free.

The use of antibiotics used in food production is associated with the appearance of resistant strains that may cause infections in humans, e.g. E. coli, Salmonella, Campilobacter and Enterococcus.

Careful attention must be paid in places where antibiotics are 
released into the environment, e.g. Manure residues from animals in stables and city waste treatment plants [20].

Making the economic case for sustainable investments that take into account the needs of every country and increasing investments in new medications, diagnostic tools, vaccines and other interventions. There are many opportunities available to reduce the unnecessary use of antibiotics, but putting such measures into practice is often problematic. Political leadership is needed in our countries [13].

There is a need for effective public policies to be implemented so that educational and information campaigns work, since the costs of investing in such campaigns are extremely high and - without involvement of the general public and healthcare professionals, so is the loss of investments that could be used to finance new research [20].

\section{New Outlooks}

What could be done to prevent the occurrence and spread of bacterial resistance?

1. Structural and chemical modification of existing antibiotics, e.g. structural modification of fluoroquinolones originating "trovafloxacim" with a much greater level of anaerobic activity. Unfortunately, recent studies have limited its use in therapy due to its grave hepatotoxic use.

2. New targets for drug actions. A number of new drugs are being derived from various sources such as frog skin, insects and pigs. Here, too, there are numerous side effects on the cells of mammals.

3. Vaccines can prevent many infectious diseases caused by antibiotic resistant bacteria. Some researchers believe that vaccines could control MRSA and reduce respiratory infections. However, despite the success achieved, there are still far too few antibiotic vaccines, e.g. the vaccine for Haemophilus influenzae that drastically reduced the incidence of meningitis. Pneumococcus vaccine, S. Aureus and Pseudomonas aeruginosa vaccines are in advanced phases of study.

4. Another possibility being studied is to use humanized monoclonal antibodies.

The general opinion among researchers is that the obstacles to producing new drugs, diagnosis and vaccines are economic rather than technological. They suggest that, to overcome this problem, there should be economic incentives and bureaucratic simplification so that both large and small pharmaceutical laboratories will invest in research to combat resistance to antibiotics [20].

\section{Conclusion}

Bacterial multi-drug resistance is a global problem and is ever more evident, but the new practices of public policies to manage public awareness campaigns are not enough, since without engagement by the general public and the healthcare community, the control and prevention plans will never be satisfactory.

Even after 60 years of antibiotics use, infectious diseases continue to have a serious effect on human mortality and public health costs. For example: In the UK, the costs of respiratory infections account for more than $50 \%$ (3.52 billion pounds) of the total of 6.07 billion in public expenditures. It is estimated that four million deaths were caused worldwide by acute respiratory infections in 2002, and that other diseases such as HIV/AIDS, diarrhea, tuberculosis and malaria caused more than seven million deaths [20].
In 2009, the ECDC estimated that infections caused by multi-drug resistant bacteria resulted in costs to healthcare departments of at least $€ 1.5$ billion and every year some 25,000 people in the U.S. die due to an infection caused by resistant bacteria. The whole world is on alert for the possibility of an epidemic since there is a critical need for the implementation of effective control and prevention measures by public policies. [sic] Research studies on the excessive use of antibiotics in the production of food animals, what the real consequences of using such drugs in animals and what are the benefits, if there really are any, and what the consequences are for human health; since the increase in bacteria found in animals produced for human consumption is worrisome, since we still do for certain what the consequences are for human health. Are antibiotics really used properly? One can see that resistance to antibiotics is the result of improper administration of drugs by healthcare professionals and indiscriminate use of drugs by the general public, which has free access to drugs. Infectious diseases that were practically eradicated are coming back, but we have not drugs to treat them. Given the mutations in the bacteria and increased rates of resistance, treating such diseases is increasingly limited [11].

\section{References}

1. Gill SR, Pop M, Deboy RT, Eckburg PB, Turnbaugh PJ, et al. (2006) Metagenomic analysis of the human distal gut microbiome. Science 312: 13551359

2. Guimarães DO, Da Silva Momesso L, Pupo MT (2010) Antibióticos: Importância terapêutica e perspectivas para a descoberta e desenvolvimento de novos agentes. Quím. Nova 33: 667-679.

3. Fernandez L, Breidenstein EBM, Hancock REW (2011) Creeping baselines and adaptive resistance to antibiotics. Drug Resist Updat 14: 1-21.

4. Høiby N, Ciofu O, Johansen KH, Song ZJ, Moser C, et al. (2011) The clinical impact of bacterial biofilms. Int J Oral Sci 3: 55-65.

5. Bjarnsholt T (2013) The Role of Bacterial Biofilms in Chronic Infections. APMIS Suppl 121: 1-51

6. A Blair, Webber JM, Baylay MA, Ogbolu AJ, Piddock LJ, et al. (2014) Molecular mechanisms of antibiotic resistance. Nat Rev Microbiol 13: 42-51.

7. Chambers HF (1999) Penicillin-Binding Protein-Mediated Resistance in Pneumococci and Staphylococci. J Infect Dis 179: S353-359.

8. Wise R, Hart T, Cars O, Streulens M, Helmuth R, et al. (1998) Antimicrobia resistance. Is a major threat to public health. BMJ (Clinical Research Ed.) 317 609-610.

9. Caumo K, Duarte M, Cargnin ST, Ribeiro BV, Tasca T, et al. (2010) Resistência bacteriana no meio ambiente e implicações na clínica hospitalar. Revista Liberato 11: 89-XX

10. Piddock LJV (2006) Multidrug-resistance efflux pumps-not just for resistance. Nat Rev Microbiol 4: 629-636.

11. EARS-NET (2014) SURVEILLANCE REPORT: Antimicrobial resistance surveillance in Europe.

12. Anvisa (2007) Resistencia microbiana-Mecanismo e impacto clinico.

13. da Saúde OM (2012) A crescente ameaça da resistência antimicrobiana Organização Mundia de Saúde 1-16.

14. Alekshun MN, Levy SB (2007) Molecular Mechanisms of Antibacterial Multidrug Resistance. Cell 128: 1037-1050.

15. Freitas F, Machado J (2012) Resistência aos Antibióticos - Uma ameaça crescente a nível europeu. Bioanálise 1: 6-7.

16. Livermore DM (2009) Has the era of untreatable infections arrived?. J Antimicrob Chemother 1: i29-36.

17. Harris SR, Feil EJ, Holden MTG, Quail MA, Nickerson EK, et al. (2010) Evolution of MRSA During Hospital Transmission and Intercontinental Spread. Science 327: 469-474

18. Fernandes $P$ (2006) Antibacterial discovery and development-the failure of success?. Nat Biotechnol 24: 1497-1503. 
Citation: da Costa ME, Machado HS (2017) Evolution of Antimicrobial Resistance in Europe: A Factual Review. J Allergy Ther 8: 250. doi:10.4172/21556121.1000250

Page 14 of 14

19. Dingle KE, Quan TP, Eyre DW, Stoesser N, Golubchik T, et al. (2017) Effects of control interventions on Clostridium diffi cile infection in England: an observational study. Lancet Infect Dis S1473-3099: 30514-X.
20. Finch R, Hunter PA (2006) Antibiotic resistance - Action to promote new technologies: Report of an EU Intergovernmental Conference held in Birmingham, UK, 12-13 December 2005. J Antimicrob Chemother 58: 12-13. 